\section{Effects of EMD liquid (Osteogain) on periodontal healing in class III furcation defects in monkeys}

Shirakata Y, Miron RJ, Nakamura T, Sena K, Shinohara Y, Horai N, Bosshardt DD, Noguchi K, Sculean A. Effects of EMD liquid (Osteogain) on periodontal healing in class III furcation defects in monkeys. J Clin Periodontol 2017; 44: 298-307. doi: 10. 1111 jicpe. 12663

\footnotetext{
Abstract

Aim: To evaluate the effect of a novel liquid carrier system of enamel matrix derivative (Osteogain) soaked on an absorbable collagen sponge (ACS) upon periodontal wound healing/regeneration in furcation defects in monkeys.

Materials and Methods: The stability of the conventional enamel matrix derivative (Emdogain) and Osteogain adsorbed onto ACS was evaluated by ELISA. Chronic class III furcation defects were created at teeth 36, 37, 46, 47 in three monkeys (Macaca fascicularis). The 12 defects were assigned to one of the following treatments: (1) open flap debridement (OFD) + ACS, (2) OFD+Emdogain/ ACS, (3) OFD+Osteogain/ACS, and (4) OFD alone. At 16 weeks following reconstructive surgery, the animals were killed for histological evaluation. Results: A $20-60 \%$ significantly higher amount of total adsorbed amelogenin was found for ACS-loaded Osteogain when compared to Emdogain. The histomorphometric analysis revealed that both approaches (OFD + Emdogain/ACS and OFD + Osteogain/ACS) resulted in higher amounts of connective tissue attachment and bone formation compared to treatment with OFD + ACS and OFD alone. Furthermore, OFD + Osteogain/ACS group showed higher new attachment formation, cementum, and new bone area.

Conclusions: Within their limits, the present data indicate that Osteogain possesses favourable physicochemical properties facilitating adsorption of amelogenin on ACS and may additionally enhance periodontal wound healing/regeneration when compared to Emdogain.
}

Yoshinori Shirakata', Richard J. Miron ${ }^{2,3}$, Toshiaki Nakamura ${ }^{1}$, Kotaro Sena ${ }^{1}$, Yukiya Shinohara ${ }^{1}$, Naoto Horai ${ }^{4}$, Dieter D. Bosshardt ${ }^{5}$, Kazuyuki Noguchi ${ }^{1}$ and Anton Sculean ${ }^{6}$

${ }^{1}$ Department of Periodontology, Kagoshima University Graduate School of Medical and Dental Sciences, Kagoshima, Japan; ${ }^{2}$ Department of Periodontology, Nova Southeastern University, Fort Lauderdale, FL, USA; ${ }^{3}$ Department of Periodontics and Oral Medicine, University of Michigan School of Dentistry, Ann Arber, MI, USA; ${ }^{4}$ Shin Nippon Biomedical Laboratories, Ltd, Kagoshima, Japan; ${ }^{5}$ Robert K. Schenk Laboratory of Oral Histology, University of Bern, Bern, Switzerland; ${ }^{6}$ Department of Periodontology, School of Dental Medicine, University of Bern, Bern, Switzerland

Key words: absorbable collagen sponge; carrier; class III furcation defect; enamel matrix proteins; periodontal regeneration

Accepted for publication 5 December 2016

\section{Conflict of interest and source of funding statement}

The authors report no conflicts of interest related to this study.

This study was partly supported by a Grant-in-Aid for Scientific Research C (No. 25463052 to Dr. Y. Shirakata) and a Grant-in-Aid for Scientific Research B (No. $15 \mathrm{H} 05036$ to Dr. K. Noguchi) from Japan Society for the Promotion of Science. The authors declare no conflict of interests regarding the materials tested in this study. The materials were kindly provided by Straumann, Basel Switzerland, and Botiss, Berlin Germany.
Pre-clinical and clinical studies have provided substantial evidence on the biologic potential of an enamel matrix derivative (EMD) to promote periodontal wound healing/regeneration and improve the clinical outcomes in intra-bony, furcation, and recession-type defects (Miron et al. 2016a). However, due to its fluid 
consistency, the use of EMD gel (Emdogain) appears to possess limited space-making potential which, in defects with a more complicated anatomy (e.g. so called non-contained-type defects), may not be able to prevent the collapse of a mucoperiosteal flap thus limiting the available space for regeneration (Mellonig 1999, Lekovic et al. 2000, Cochran et al. 2003, Shirakata et al. 2007). In order to overcome these potential shortcomings, clinicians often combine various types of bone grafting materials with Emdogain, especially when treating non-contained-type defects (Sculean et al. 2011). The combination of Emdogain and different types of grafting materials has been extensively evaluated in pre-clinical and clinical studies (Lekovic et al. 2000, Cochran et al. 2003, Shirakata et al. 2007, Gurinsky et al. 2004, Bokan et al. 2006, Kuru et al. 2006, Yilmaz et al. 2010). Although a recent systematic review reported that the combination of Emdogain with bone grafting materials may lead to statistically significantly higher clinical improvements, the analysis also revealed a high heterogeneity between the clinical outcomes obtained with the various combination approaches (Matarasso et al. 2015). One possible reason for the high clinical variability in the outcomes when using the combination of Emdogain and grafting materials may be related to substantial differences in enamel matrix proteins (EMPs) adsorption and subsequent cell proliferation between the utilized bone grafting materials (Miron et al. 2015). In this respect, very recent data from a series of in vitro studies revealed that the use of EMD without its propylene-glycol-alginate (PGA) carrier markedly improved protein adsorption when compared to conventional EMD (e.g. Emdogain) (Miron et al. 2015). Further advantages of using EMD without its PGA carrier is related to its more fluid consistency and subsequent improvement of surface coating and penetration of EMPs within the bone biomaterials coupled with the capacity for a gradual release of EMPs over time (Miron et al. 2015). These prominent findings led to the development of a new liquid carrier system for EMD (Osteogain) specifically designed for mixing it with different biomaterials including bone grafts and collagen matrices/scaffolds. Very recently, Miron et al. (2016b) reported that pre-coating Osteogain onto a natural bovine mineral (NBM) significantly increased cell adhesion, proliferation, and differentiation of osteoblasts in vitro (Miron et al. 2016b) and improved new bone formation in a rat femur bone defect model (Zhang et al. 2016). However, despite these encouraging data, it is still unclear to what extent Osteogain is effective in promoting periodontal wound healing/regeneration in periodontal defects.

An important aspect that is still controversially discussed in the literature is the need of using bone grafting materials for enhancing periodontal regeneration. Since most findings from histological studies in animals and humans indicate that the healing following the use of bone grafting materials is frequently characterized by persistence of grafting residues embedded either in bone or encapsulated in connective tissue, the biologic rationale of using such materials needs to be questioned (Ivanovic et al. 2014, Sculean et al. 2015). Thus, although clinical consequences of persisting graft residues are still unclear, from a biological point of view, it would be desirable that a biomaterial used as a carrier for biologics (e.g. growth factors or EMD) or to stabilize the wound by supporting the flap, is completely resorbed and replaced by regenerated periodontal tissues (e.g. cementum, periodontal ligament, and bone). During the last decades various types of collagens matrices have been successfully used as carriers for growth factors and Emdogain, pointing to the potential biological advantages of this combination to support wound healing/regeneration (Susin et al. 2015, Stähli et al. 2016).

However, at present, it is unknown whether the combination of EMD and an absorbable collagen sponge (ACS) may represent a potential option for reconstructive surgery in complex non-contained defects such as class III furcation defects. Therefore, the aim of the present pre-clinical study was to evaluate the effects of Osteogain with ACS in chronic class III furcation defects in non-human primates.

\section{Materials and Methods}

\section{Emdogain, Osteogain, and ACSs}

Emdogain and Osteogain $(0.3 \mathrm{ml}$ vials, concentration $30 \mathrm{mg} / \mathrm{ml}$; Straumann AG, Basel, Switzerland) and native type I and III porcine absorbable collagen sponges (ACS: Collacone $^{\circledR}$; Botiss, Berlin, Germany) were utilized in this study.

\section{Quantification of amelogenin adsorption to ACSs}

To determine the quantity of Emdogain/Osteogain adsorption to the surface of ACSs, ELISA quantification assay was utilized for amelogenin, the main protein found in EMD encompassing $90-95 \%$ of the total protein content. Briefly, $0.3 \mathrm{ml}$ of Emdogain/ Osteogain was poured onto cylindrical ACS scaffolds in six-well dishes for $10 \mathrm{~min}$ at $37^{\circ} \mathrm{C}$. After the coating period incubation, the samples were simply washed with phosphate-buffered saline (PBS), and the remaining PBS solution containing unattached enamel matrix proteins was collected and quantified by a Quantikine Colorimetric Sandwich ELISA (Porcine Amelogenin, $\mathrm{X}$ isoform (AMELX) ELISA Kit; MyBioSource Inc, San Diego, CA, USA) according to the manufacturer's protocol. Subtraction of total coated protein from the amount of unadsorbed protein was used to determine the amount of adsorbed material to the surface of ACS as previously described (Miron et al. 2015). Furthermore, in order to determine the quantity of amelogenin protein being released from ACS over time, coated ACSs were soaked in $5 \mathrm{ml}$ of PBS and samples were collected at various time points including 15 min, $1 \mathrm{~h}, 8 \mathrm{~h}, 1,3$, and 10 days. All samples were quantified in triplicate and three independent experiments were performed.

\section{Experimental animals}

Three 7-8-year old male monkeys (Macaca fascicularis), weighing 6.91$7.02 \mathrm{~kg}$, were used. The animals exhibited intact dentition with healthy periodontium. They were kept in individual cages at $23-29^{\circ} \mathrm{C}$, relative humidity of $30-70 \%$, and a 12-hour light/dark cycle. Approximately, $108 \mathrm{~g}$ of solid food (HF Primate J 
12G 5K9J, Purina Mills, LLC, Gray Summit, MO, USA) was provided to each animal daily and water was available ad libitum. All procedures during the in-life phase for about 9 months (from 6 November 2014 to 3 August 2015) were approved by the ethical committee of the Animal Research Center of Kagoshima University, Japan (approval no. D14026) and were performed in accordance with standards published by the National Research Council (Guide for the Care and Use of Laboratory Animals, NIH OACU) of the National Institutes of Health Policy on Human Care and Use of Laboratory Animals.

\section{Preparation of experimental defects}

One surgeon (Y. S) performed all surgical procedures under general and local anaesthesia using aseptic routines. Before the operation, buprenorphine hydrochloride (Lepetan injection $0.2 \mathrm{mg}$; Otsuka Pharmaceutical Co., Ltd, Tokyo, Japan, $0.1 \mathrm{ml} / \mathrm{Kg}$ ), to ameliorate pain, and an antibiotic (Mycilinzol Meiji, $0.05 \mathrm{ml} / \mathrm{kg}$; Meiji Seika Pharma Co., Ltd, Tokyo, Japan), to prevent infection, were administered intramuscularly. General anaesthesia was achieved with a ketamine hydrochloride $(0.2 \mathrm{ml} / \mathrm{kg}$ IM; Supriya Lifescience Ltd, Mumbai, India)/medetomidine hydrochloride (Domitor, 0.08 ml $/ \mathrm{kg} \mathrm{IM;} \mathrm{Orion} \mathrm{Cor-}$ poration, Espoo, Finland) combination maintaining spontaneous breathing. Local anaesthesia was performed using lidocaine $\mathrm{HCl}$ /epinephrine $(2 \%, 1: 80,000$; Xylocaine, Fujisawa Inc., Osaka, Japan). After the operation, atipamezole hydrochloride (Antisedan, $0.08 \mathrm{ml} / \mathrm{kg}$, Orion Corporation) was administered intramuscularly. Ketoprofen (Capisten IM $50 \mathrm{mg}$, $2 \mathrm{mg} / \mathrm{kg}, 0.1 \mathrm{ml} / \mathrm{kg}$; Kissei Pharmaceutical Co., Ltd, Matsumoto, Japan), to ameliorate pain, and an antibiotic (Mycilinzol Meiji, $0.05 \mathrm{ml} / \mathrm{kg}$; Meiji Seika Pharma Co., Ltd), to prevent infection, were intramuscularly administered to all animals for 2 days after operation.

As a pre-treatment, the second premolars and third molars in the mandible were extracted for flap management to prevent material exposure and obtain primary closure as previously described (Donos et al.2003, Gkranias et al. 2012). After a healing period of 2 months, the mucoperiosteal flaps were raised and class III furcation defects were surgically created at the first and the second mandibular molars with the use of bone chisels and slowly rotating diamond burs (12 defects in total). The dimensions of the exposed furcation defects were $5 \mathrm{~mm}$ wide and $5 \mathrm{~mm}$ high. In order to prevent spontaneous healing and induce plaque accumulation, the defects were filled with impression materials (EXAFINE PUTTY TYPE, GC Corporation, Tokyo, Japan) (Fig. 1a). Subsequently, the flaps were repositioned and stabilized with 4-0 silk sutures (Mersilk $^{\mathrm{TM}}$; Ethicon Ltd, Edinburgh, UK). Sutures were removed at 10 days following surgery. During 8 weeks following the first surgery, no oral hygiene measures were performed and the animals were fed a soft diet. After 8 weeks, the impression material was removed from the defects and a plaque control regimen, consisting of oral cavity flushing with a chlorhexidine gluconate solution $\left(5 \%\right.$ HIBITANE ${ }^{\circledR}, 25 \mathrm{ml}$ of a $2 \%$ solution; Sumitomo Dainippon Pharma Co., Ltd., Osaka, Japan) was performed for a period of 4 weeks.

\section{Reconstructive surgery}

At 16 weeks following creation of the defects (Fig. 1b), intra-sulcular incisions were performed and full-thickness buccal and lingual flaps were elevated in order to expose the furcation defects. All granulation tissue (Fig. 1c) was removed and the exposed root surface was carefully scaled and planed. Cementum was removed using Gracey curettes and a chisel (Fig. 1d). Reference notches were made using a \#1 round bur on the root surface at the base of the defects for histometric analysis. Class III furcation defects received one of the following treatments: ACS alone, Emdogain with ACS (Emdogain/ ACS), Osteogain with ACS (Osteogain/ACS), and open flap debridement (OFD) as a surgical control. The experimental conditions were rotated between defect sites in subsequent animals. Emdogain/ACS and Osteogain/ACS were not placed in the same unilateral side in the same animal. In the ACS group, ACS was mixed with sterile saline before being applied to the defect. Root surfaces that received Emdogain or Osteogain were conditioned with a $24 \%$ EDTA gel $\left(\right.$ PrefGel $^{\circledR}$; Straumann AG) for 2 min and then, along with the adjacent mucoperiosteal flaps, thoroughly rinsed with sterile saline. Prior to the placement of Emdogain/ACS or Osteogain/ACS, the ACS was fully saturated with Emdogain or Osteogain and the constructs were allowed to rest for $10 \mathrm{~min}$ (Fig. 1e). The constructs were then filled in the defect with moderate pressure (Fig. 1f). Maximum care was taken during surgery to prevent mixing of Emdogain or Osteogain to the other site in the same side of the mandible.

A periosteal releasing incision was made to allow coronal displacement of the flap, followed by suturing (Gore-Tex CV-6 Suture; W.L. Gore \& Associates Inc., Flagstaff, AZ, USA) slightly coronal to the CEJ (Fig. 1g). After reconstructive surgery, the animals received similar treatments of the antibiotics and analgesics which were used during preparation of experimental defects. Sutures were removed after 14 days of healing and postoperative plaque control was maintained as previously described. Then, 4 months after the reconstructive surgery (Fig. 1h) the animals were anesthetized by an intravenous injection of sodium pentobarbital $\quad(64.8 \mathrm{mg} / \mathrm{ml}, \quad 0.4 \mathrm{ml} / \mathrm{kg}$; Tokyo Chemical Industry Co., Ltd, Tokyo, Japan) and killed by exsanguination.

\section{Histological processing}

All the defects, including the experimental and control sites, were then dissected with the surrounding soft and hard tissues. The tissue blocks were fixed in $10 \%$ buffered formalin, trimmed, and rinsed in PBS. The samples were decalcified in Kalkitox $^{\mathrm{TM}}$ solution (Wako Pure Chemical Industries Ltd., Osaka, Japan) for 3 weeks, dehydrated, and embedded in paraffin. Step serial sections of $6 \mu \mathrm{m}$ thickness were then prepared along the mesio-distal plane, stained with haematoxylin/eosin or with Azan-Mallory at intervals of $90 \mu \mathrm{m}$.

\section{Histometric analysis}

All the specimens were analysed histometrically under a light microscope (Eclipse E800; Nikon Inc., Tokyo, 

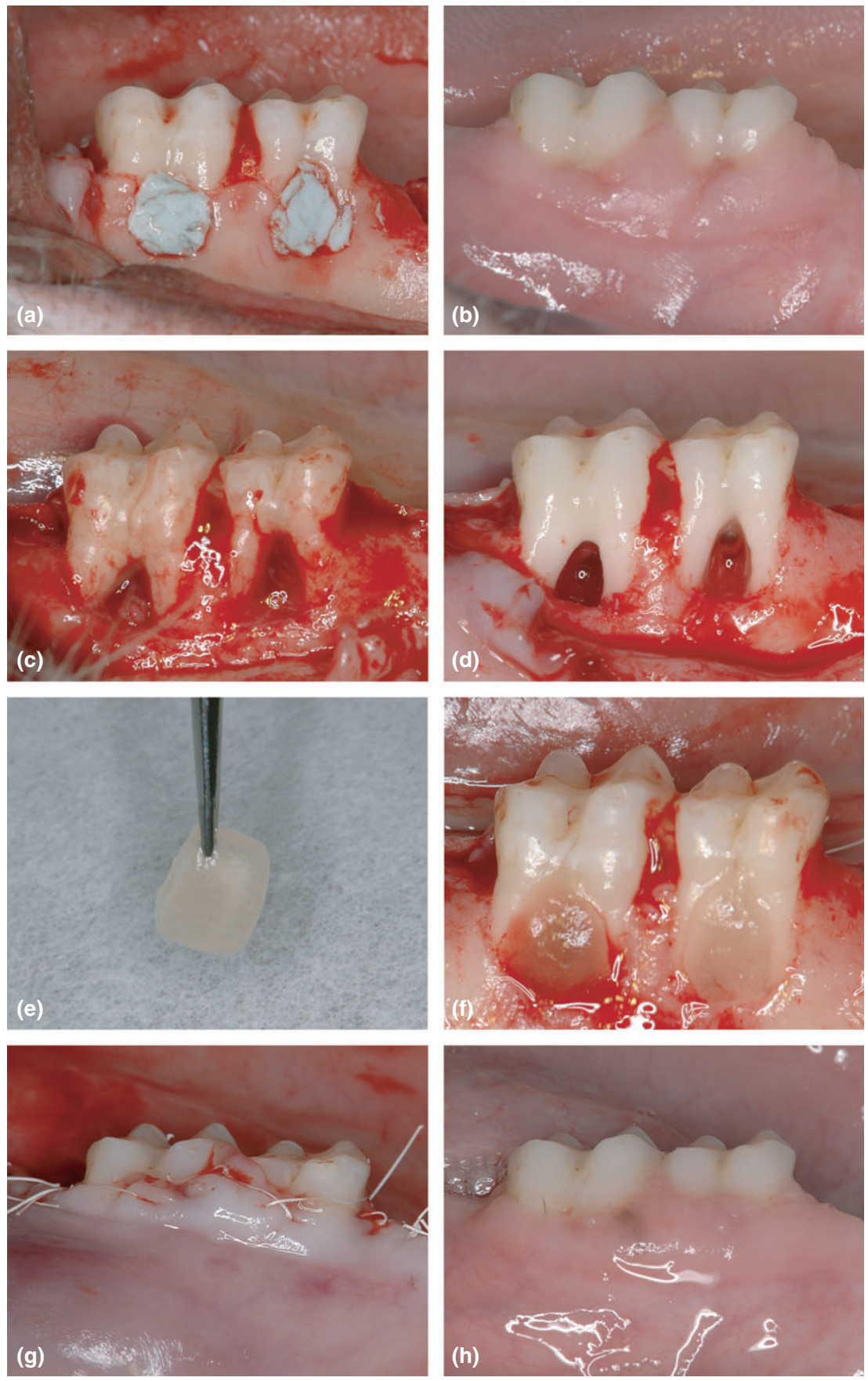

Fig. 1. Clinical appearance of the mandibular buccal aspect of Macaca fascicularis. (a) Induction of chronic inflammation. After fabrication of Class III furcation defects, impression materials were placed to encourage growth of oral microflora along the exposed root surfaces. (b) Prior to reconstructive surgery. (c) Immediately after flap reflection. Note the excessive granulation tissue in the chronic defects. (d) Defects were exposed and debrided again at the time of reconstructive surgery. (e) Osteogain/absorbable collagen sponge (ACS) construct before surgical implantation. (f) left (second molar): ACS alone, right (first molar): placement of Osteogain/ACS. (g) Flaps were coronally repositioned and sutured. (h) 16 weeks after reconstructive surgery.

Japan) equipped with a computerized imaging system (Image-pro Plus Media Cybernetics, Silver Spring, MD, USA). For the histometric analysis, three sections approximately
$90 \mu \mathrm{m}$ apart were selected from the most central area of each class III furcation defect, identified by the length of the root canal and the reference notches. A line connecting both notches defined the apical limit of the defect and the following parameters were measured by the same experienced and masked examiner (T. N.). The mean value of each histometric parameter was then calculated for each site.

Area measurements (in $\mathrm{mm}^{2}$ and \%)

1 Bone defect area (BDA): area limited by the apical line and the root surface in the furcation region;

2 Non-filled area (NFA): portion of the BDA not filled with any tissue, partially filled with plaque deposited on the root surface;

3 Epithelium tissue area (ETA): portion of the BDA filled with epithelium tissue;

4 Connective tissue area (CTA): portion of the BDA filled with connective tissue;

5 New bone area (NBA): portion of the BDA filled with new bone

Area measurements, except for BDA, were calculated as the percentage of the BDA within each defect.

Linear measurements (in $\mathrm{mm}$ and \%)

1 Length of the root surface (LRS): length of the root surface from the mesial notch to the distal notch;

2 Tissue-free defect length (TFL): portion of the LRS with the absence of any new tissue formation;

3 Junctional epithelial migration (JE): total linear extensions of the root surface covered by epithelial tissue;

4 Connective tissue adhesion (CT): total linear extensions of the root surface covered by connective tissue without cementum;

5 New cementum formation (NC): total linear extensions of the root surface coved by new cementum:

6 New attachment formation (NA): total linear extensions of the root surface covered by $\mathrm{NC}$ adjacent to newly formed bone, with functionally oriented collagen fibres

Linear measurements, except for LRS, were also expressed as the percentage of the LRS within each defect.

\section{Examiner calibration}

Thirty-six sections from all sites were read by the examiner without calibration before the measurements. 
Forty-eight hours later, the same examiner read all 36 sections again to evaluate intra-examiner reproducibility. Inter-calibration of the examiner was accepted at the $90 \%$ level. Because of low sample size due to the selected model chosen, the statistical analysis was restricted to descriptive statistics.

\section{Statistical analysis} cation experiments, means and standard errors (SE) were calculated. Statistically significant differences were examined by multiple $t$-tests between both groups. Statistical significance was defined as a $p$-value of 0.05 corrected using the BonferroniDunn method utilizing GraphPad Prism software (La Jolla, CA, USA).

\section{Results}

\section{Ability to adsorb and release Emdogain} and Osteogain over time

ELISA was utilized to investigate the amount of adsorbed amelogenin when Emdogain or Osteogain were loaded onto ACS (Fig. 2). While it was first found that both carriers efficiently loaded amelogenin onto the collagen sponges at time point 0 , a simple saline rinse with PBS significantly removed over $20 \%$ more (from $>90 \%$ to $70 \%$ ) of the total amelogenin content from Emdogain when compared to Osteogain where the total protein content remained $<90 \%$ of the initial concentrations (Fig. 2). At each of the remaining time points thereafter, a $20-60 \%$ significantly higher amount of total adsorbed amelogenin was found for collagen sponges loaded with Osteogain when compared to Emdogain
For the amelogenin ELISA quantifi-

(Fig. 2). After a 10-day period, nearly $60 \%$ of the initial amelogenin protein content found in Osteogain remained present within the collagen sponges, whereas in the Emdogain samples, no remaining amelogenin could be quantified as values approached $0 \%$ (Fig. 2).

\section{Clinical observations}

All surgical treatments were well tolerated by the animals, and clinical healing was uneventful at all 12 sites. No visible adverse reactions including material exposure, infection, and suppuration were observed throughout the experimental period.

\section{Histological observations}

OFD group

In the OFD group, apical migration of the junctional epithelium considerably occurred (Fig. 3a,e,i) with varying degrees of new attachment, and new bone formation was observed. In one defect, considerable new cementum formation and moderate new attachment formation occurred (Fig. 3a). Artefacts (separations between the new cementum and the root surface) were consistently detected in all three defects. Thick new cellular cementum with or without collagen fibres obliquely oriented to the root surface was seen in the lower portion of the defect (Fig. 4a,b). The collagen fibres appeared to be sparser than those observed in the Emdogain/ACS and Osteogain/ACS groups (Figs 3e,i and $4 \mathrm{~b})$.

\section{ACS group}

The healing pattern in the ACS group was characterized by limited periodontal regeneration (Fig. 3b, f

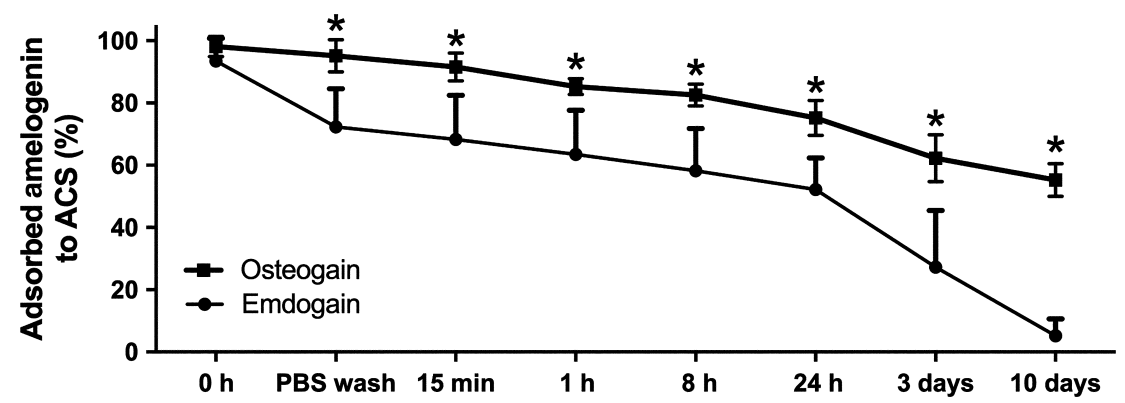

Fig. 2. In vitro release profiles of Emdogain and Osteogain from absorbable collagen sponge. $(*, p$ values $<0.05$ was considered significant). and j). Junctional epithelium migrated to the most coronal extension of new cementum with less connective tissue adhesion (Fig. 4c,d). A small amount of new bone formed in the lower portion of the defect (Fig. 3b,f,j). New cementum formation and new attachment formation were minimal in one defect, and restricted to the mid portion of the rest of two defects. Moderate thick and thin cellular cementum with or without collagen fibres obliquely oriented to the root surface was observed (Fig. 4c,d).

\section{Emdogain/ACS group}

In the Emdogain/ACS group, apical extension of the junctional epithelium was more restrained than in the OFD and ACS groups. A greater amount of new cementum was observed in the EMD group than in the control and ACS groups. New bone formation was noted extending from the apical notch towards the coronal region of the defect (Fig. 3g, $\mathrm{k})$. Thin acellular cementum and thick cellular cementum, with collagen fibres obliquely oriented to the root surfaces, were observed (Fig. 4e,f). Furthermore, the collagen fibres appeared to be denser than those observed in the OFD and ACS groups. Many blood vessels were observed within the newly formed periodontal ligament (Fig. 4e,f).

\section{Osteogain/ACS group}

In general, the healing pattern in the Osteogain/ACS group was similar to the Emdogain/ACS group. However, migration of junctional epithelium was more restrained in the Osteogain/ACS group than in the OFD, ACS, and Emdogain/ACS groups. Furthermore, new attachment and new bone formation were consistently noted extending from the apical notches towards the coronal region of the defect in all defects (Fig. 3d,h, 1). Moderately thick new cellular and thin acellular cementum, with dense collagen fibres obliquely or perpendicular oriented to the denuded root surface was more consistently observed (Fig. 4g, h). Highly vascularized new periodontal ligament-like tissue, tightly confined to between the new cementum and new bone, maintained its width up to the coronal portion (Fig. 4g,h). 


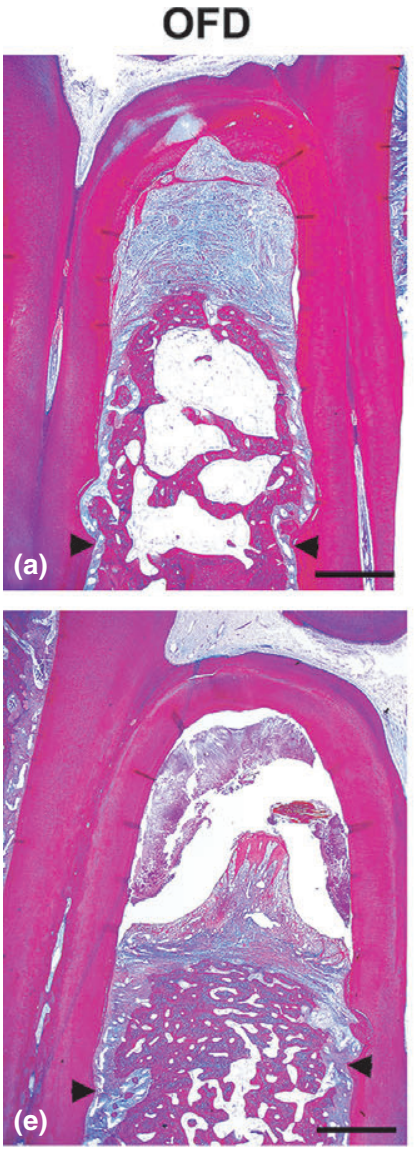

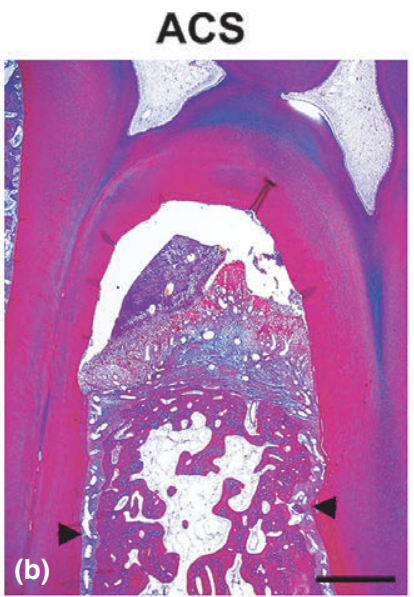

Emdogain/ACS
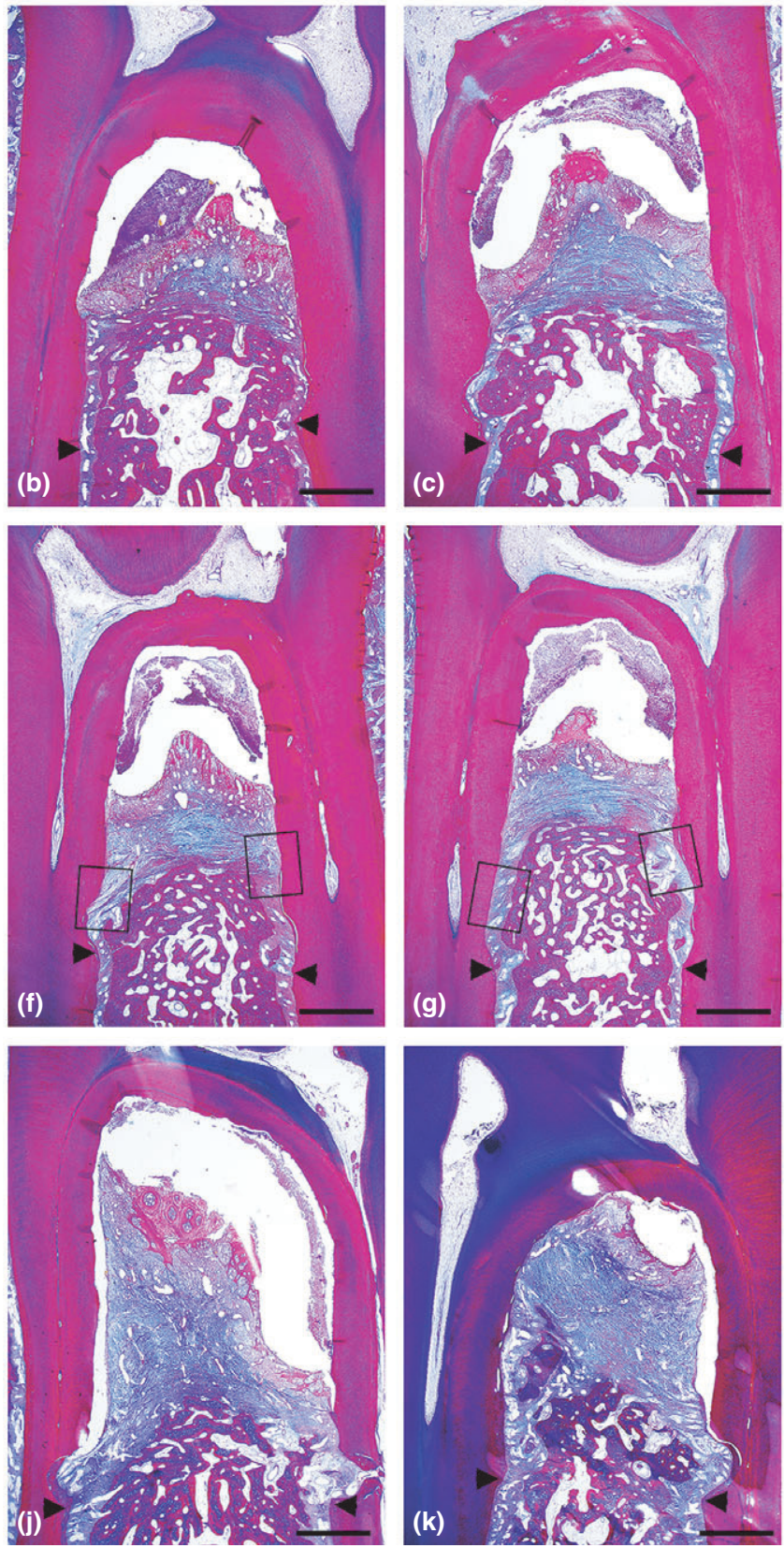
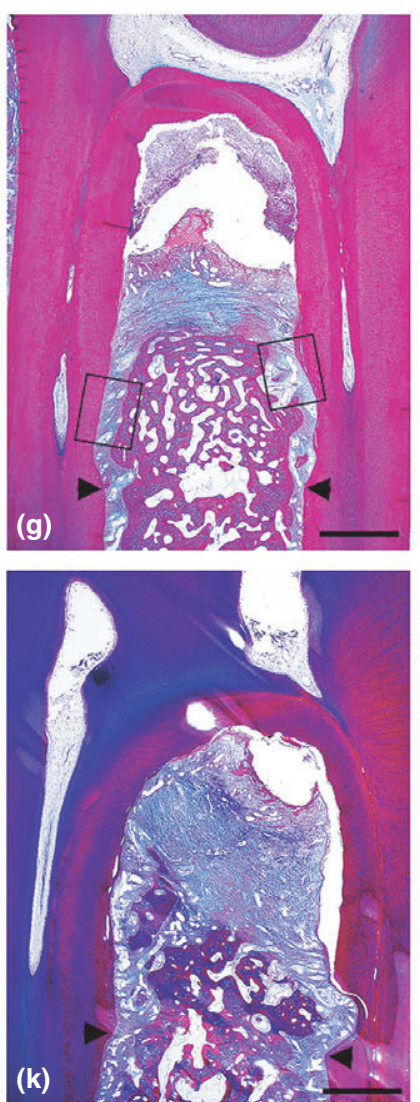

Osteogain/ACS
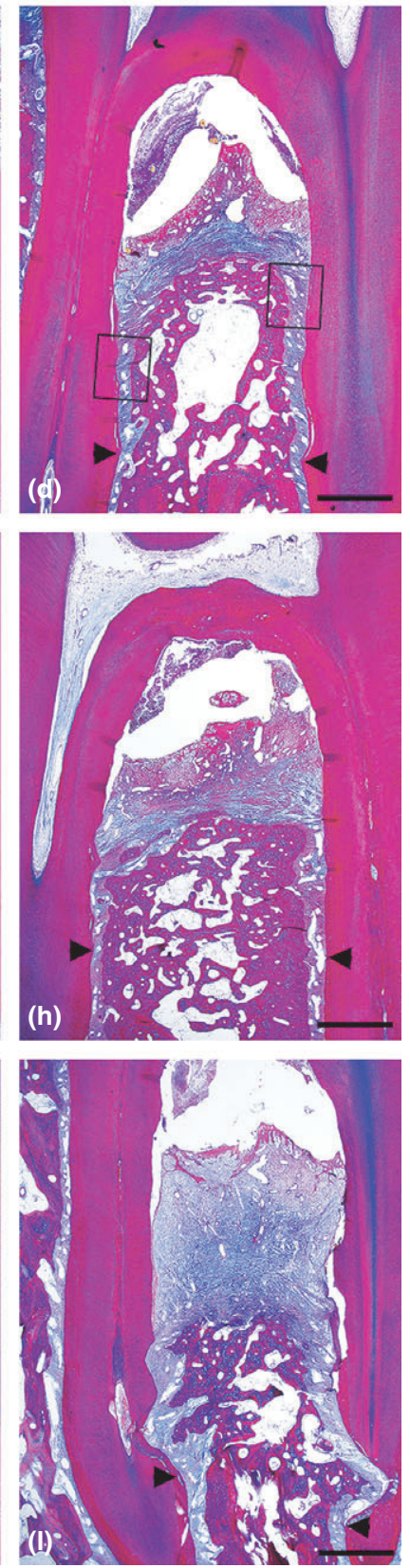

Fig. 3. Overview photomicrographs of all Class III furcation defects in different groups (Azan-Mallory staining). (a), (e), and (i): Open flap debridement (OFD) group Overview. (scale bar: $1 \mathrm{~mm}$ ). (b), (f), and (j): Absorbable collagen sponge (ACS) group Overview. (scale bar: $1 \mathrm{~mm})$. (c), (g), and (k): Emdogain/ACS group Overview. (scale bar: $1 \mathrm{~mm})$. (d), (h), and (l): Osteogain/ACS group Overview. (scale bar: $1 \mathrm{~mm}$ ). Arrowhead: notch (apical extent of root planing).

ACS appeared to be completely resorbed after 16 weeks of healing in the ACS, Emdogain/ACS, and Osteogain/ACS groups. Complete defect resolution of furcation defects was not achieved in any of defects in all four treatment groups. There was neither extensive root resorption nor ankylosis, irrespective of the experimental group.

\section{Histometric analysis}

The results of histometric analysis are summarized in Tables 1 and 2. The ETA/BDA in the Emdogain/ACS $(14.6 \pm 2.7 \%)$ and Osteogain/ACS $(14.3 \pm 1.5 \%)$ groups were lower than those in the OFD $(19.2 \pm 3.9 \%)$ and ACS $(21.7 \pm 3.2 \%)$ groups. Osteogain/ACS group showed the greatest amount of newly formed bone (NBA/BDA) among the groups examined. The length of junctional epithelium migration observed in the Osteogain/ACS group was shorter than those in the OFD, ACS, and Emdogain/ACS groups. The Emdogain/ACS and Osteogain/ACS groups showed greater cementum formation than the ACS group. The amount of 


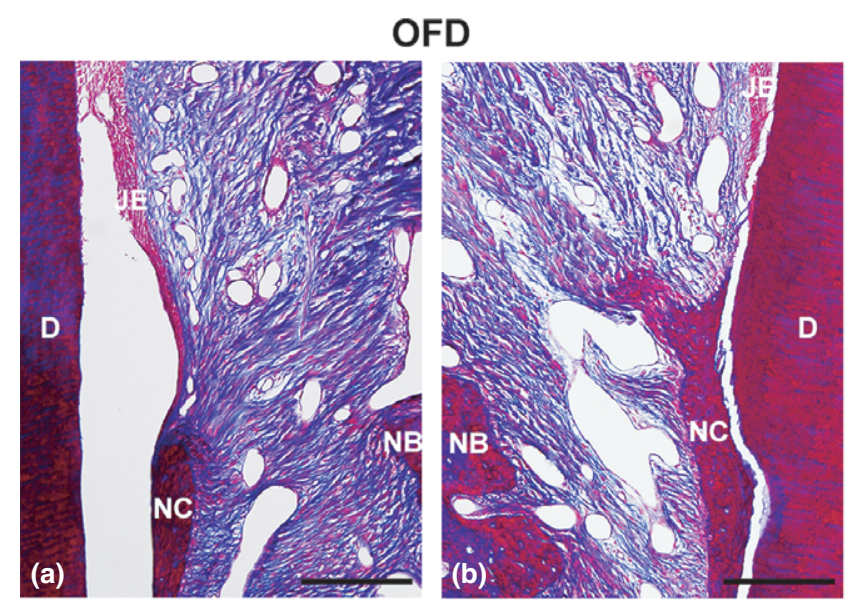

Emdogain/ACS
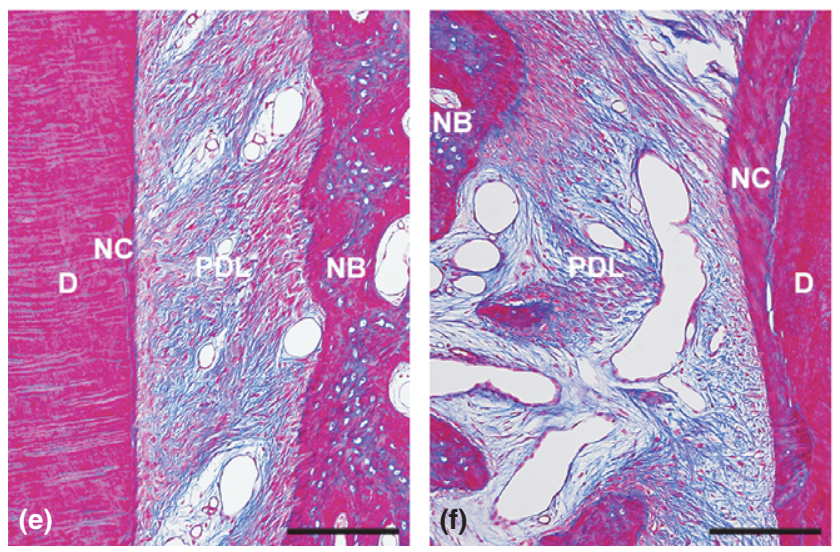

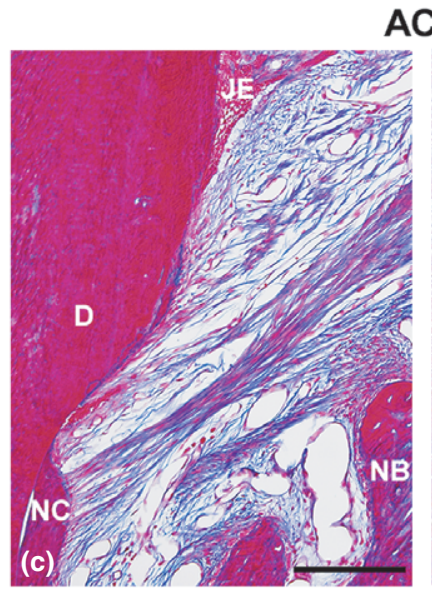

ACS

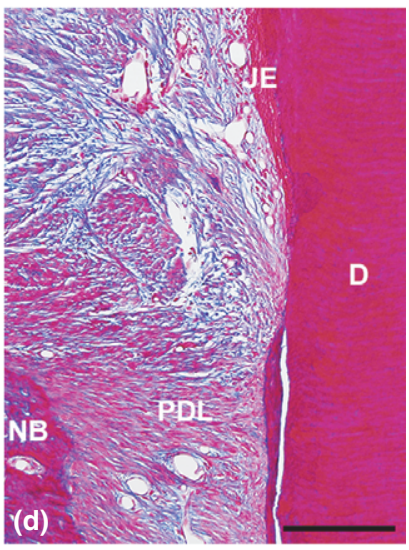

Osteogain/ACS

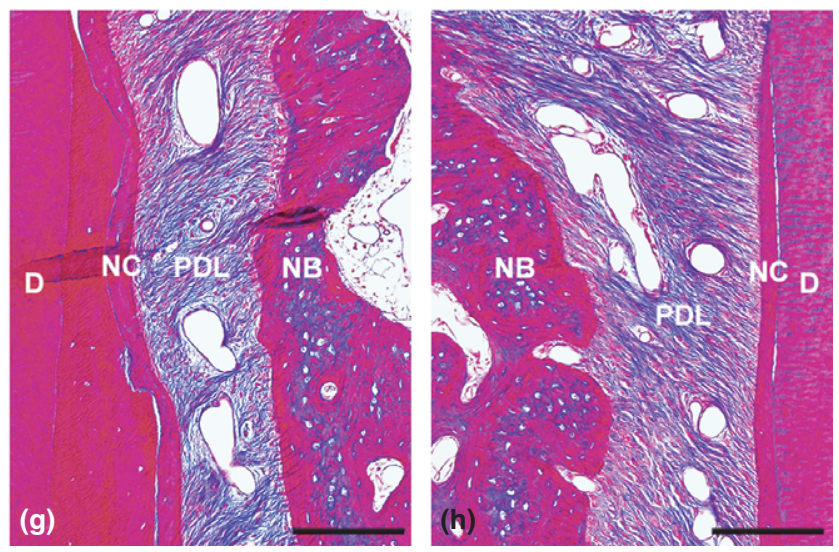

Fig. 4. Representative photomicrographs of Class III furcation defects in open flap debridement (OFD) group (Azan-Mallory staining). (a) Higher magnification of the framed area (left) in Fig. 3i (scale bar: $200 \mu \mathrm{m}$ ), (b) Higher magnification of the framed area (right) in Fig. 3i (scale bar: $200 \mu \mathrm{m}$ ), in ACS group (c) Higher magnification of the framed area (left) in Fig. 3f (scale bar: $200 \mu \mathrm{m}$ ), (d) Higher magnification of the framed area (right) in Fig. 3f (scale bar: $200 \mu \mathrm{m}$ ), in Emdogain/ACS group (e) Higher magnification of the apical framed area (left) in Fig. 3g, (f) Higher magnification of the framed area (right) in Fig. $3 \mathrm{~g}$ (scale bar: $200 \mu \mathrm{m}$ ), and in Osteogain/ACS group (g) Higher magnification of the framed area (left) in Fig. 3d (scale bar: $200 \mu$ m), (h) Higher magnification of the framed area (right) in Fig. 3d (scale bar: $200 \mu \mathrm{m}$ ). JE: junctional epithelium, NB: new bone, D: root dentin, NC: new cementum, PDL: periodontal ligament.

new cementum in the Osteogain/ACS group $(40.5 \pm 7.2 \%)$ was twice as great as in the ACS group (19.4 \pm $7.5 \%)$. Moreover, new attachment formation was most extensive in the Osteogain/ACS $(37.4 \pm 4.6 \%)$ group when compared to the OFD $(19.4 \pm 6.9 \%), \operatorname{ACS}(14.1 \pm 9.6 \%)$, and Emdogain/ACS $(25.0 \pm 1.8 \%)$ groups.

\section{Discussion}

To the best of our knowledge, this is the first report evaluating the potential effects on periodontal wound healing/regeneration of a new liquid carrier system for EMD (Osteogain) in chronic class III furcation defects in non-human primates. Many investigators have become interested in the plausible reasons for the high clinical variability for studies reporting the combination of EMD with bone grafting materials $(\mathrm{Tu}$ et al. 2010, Miron et al. 2014). Previous data have shown that the use of Emdogain, although ideal for root surface adsorption, displayed drastically increased thickness of coating to the bone grating surface which was easily dissolved following a simple PBS rinse. Contrarily, the use of Osteogain (EMD dissolved in acetic acid solution) exhibited more favourable surface coating by demonstrating an increase and more complete surface loading of porous graft materials and tighter and more stable surface coatings with enamel matrix proteins (Miron et al. 2015).
In this study, we used ACS as a putative carrier for EMD since ACS has been extensively used as an appropriate carrier including high clinical applicability, biocompatibility, and uneventful biodegradation in bone and periodontal surgeries (McPherson 1992, Cochran et al. 2000, Yamashita et al. 2010, Kim et al. 2013). In addition, it has been reported that the fast resorption of a residual material is desirable to avoid the risk for infection and to increase the amount of regenerated tissues in bone/periodontal defects (MacNeill et al. 1999, Shirakata et al. 2002, 2007, Potijanyakul et al. 2010, Yoshinuma et al. 2012). Histological findings demonstrated that ACS was completely resorbed after 16 weeks of healing in the ACS, Emdogain/ACS, 
Table 1. Histomorphometric area measurement in each group (mean $\pm \mathrm{SD}$ in $\mathrm{mm}^{2}$ and $\% ; n=3$ animals, $n=12$ sites)

\begin{tabular}{|c|c|c|c|c|c|}
\hline \multirow[t]{2}{*}{ Histometric parameter } & \multirow[t]{2}{*}{ Animal No } & \multicolumn{4}{|c|}{ Experimental condition } \\
\hline & & Control & ACS & Emdogain/ACS & Osteogain/ACS \\
\hline \multirow[t]{4}{*}{$\mathrm{BDA}\left(\mathrm{mm}^{2}\right)$} & 1 & 12.3 & 11 & 16.2 & 12.7 \\
\hline & 2 & 13.1 & 10.2 & 11.6 & 14.5 \\
\hline & 3 & 12.1 & 18 & 11.6 & 17.5 \\
\hline & Mean $\pm \mathrm{SD}$ & $12.5 \pm 0.5$ & $13.1 \pm 4.3$ & $13.1 \pm 2.7$ & $15.0 \pm 2.4$ \\
\hline \multirow[t]{4}{*}{ NFA in $\mathrm{mm}^{2}$ and $(\%)$} & 1 & $0(0.4)$ & $2.7(25.0)$ & $4.9(30.3)$ & $3.2(25.6)$ \\
\hline & 2 & $5.9(45.4)$ & $3.1(30.5)$ & $3.4(28.8)$ & $2.6(17.7)$ \\
\hline & 3 & $1.5(12.4)$ & $5.2(28.6)$ & $1.1(9.5)$ & $4.2(24.3)$ \\
\hline & Mean $\pm \mathrm{SD}$ & $2.5 \pm 3.1(19.4 \pm 23.4)$ & $3.7 \pm 1.3(28.0 \pm 2.8)$ & $3.1 \pm 1.9(22.9 \pm 11.6)$ & $3.4 \pm 0.8(22.5 \pm 4.3)$ \\
\hline \multirow[t]{4}{*}{ ETA in $\mathrm{mm}^{2}$ and $(\%)$} & 1 & $2.5(20.5)$ & $2.6(23.8)$ & $2.4(14.7)$ & $1.6(13.0)$ \\
\hline & 2 & $1.9(14.8)$ & $1.8(17.9)$ & $1.4(11.9)$ & $2.1(14.1)$ \\
\hline & 3 & $2.7(22.4)$ & $4.2(23.3)$ & $2.0(17.2)$ & $2.8(15.9)$ \\
\hline & Mean $\pm \mathrm{SD}$ & $2.4 \pm 0.4(19.2 \pm 3.9)$ & $2.9 \pm 1.2(21.7 \pm 3.2)$ & $1.9 \pm 0.5(14.6 \pm 2.7)$ & $2.2 \pm 0.6(14.3 \pm 1.5)$ \\
\hline \multirow[t]{4}{*}{ CTA in $\mathrm{mm}^{2}$ and $(\%)$} & 1 & $2.0(16.7)$ & $1.4(13.1)$ & $2.4(14.7)$ & $1.2(9.5)$ \\
\hline & 2 & $1.3(9.6)$ & $1.9(18.4)$ & $1.4(11.9)$ & $1.8(12.1)$ \\
\hline & 3 & $2.4(20.1)$ & $3.8(21.0)$ & $2.9(25.3)$ & $3.2(18.2)$ \\
\hline & Mean $\pm \mathrm{SD}$ & $1.9 \pm 0.6(15.4 \pm 5.4)$ & $2.4 \pm 1.2(17.5 \pm 4.0)$ & $2.2 \pm 0.8(17.3 \pm 7.1)$ & $2.1 \pm 1.0(13.3 \pm 4.5)$ \\
\hline \multirow{4}{*}{ NBA in $\mathrm{mm}^{2}$ and $(\%)$} & 1 & $3.2(26.3)$ & $3.8(34.5)$ & $5.4(33.4)$ & $5.4(42.4)$ \\
\hline & 2 & $3.2(24.1)$ & $2.8(27.1)$ & $4.3(37.0)$ & $6.9(47.2)$ \\
\hline & 3 & $4.1(34.3)$ & $3.1(17.2)$ & $3.6(30.9)$ & $5.3(30.2)$ \\
\hline & Mean \pm SD & $3.5 \pm 0.6(28.3 \pm 5.3)$ & $3.2 \pm 0.5(26.3 \pm 8.7)$ & $4.4 \pm 0.9(33.8 \pm 3.0)$ & $5.8 \pm 0.9(39.9 \pm 8.8)$ \\
\hline
\end{tabular}

ACS, absorbable collagen sponge; BDA, bone defect area; NFA, non-filled area; ETA; epithelium tissue area; CTA, connective tissue area; NBA, new bone area.

Table 2. Histomorphometric linear measurement in each group (mean $\pm \mathrm{SD}$ in $\mathrm{mm}$ and $\% ; n=3$ animals, $n=12$ sites)

\begin{tabular}{|c|c|c|c|c|c|}
\hline \multirow[t]{2}{*}{ Histometric parameter } & \multirow[t]{2}{*}{ Animal No } & \multicolumn{4}{|c|}{ Experimental condition } \\
\hline & & Control & ACS & Emdogain/ACS & Osteogain/ACS \\
\hline \multirow[t]{4}{*}{ LRS (mm) } & 1 & 12.3 & 10.1 & 13.1 & 12 \\
\hline & 2 & 11.3 & 10.7 & 11.7 & 12.3 \\
\hline & 3 & 12.2 & 14.5 & 10.9 & 16.5 \\
\hline & Mean \pm SD & $11.9 \pm 0.5$ & $11.8 \pm 2.4$ & $11.9 \pm 1.1$ & $13.6 \pm 2.5$ \\
\hline \multirow[t]{4}{*}{ TFL in $\mathrm{mm}$ and $(\%)$} & 1 & $1.4(11.6)$ & $5.8(57.2)$ & $7.0(53.8)$ & $5.4(44.6)$ \\
\hline & 2 & $7.9(69.8)$ & $5.5(51.7)$ & $5.7(48.6)$ & $5.5(45.1)$ \\
\hline & 3 & $3.8(31.0)$ & $7.3(50.5)$ & $4.6(42.2)$ & $7.3(44.3)$ \\
\hline & Mean $\pm \mathrm{SD}$ & $4.4 \pm 3.3(37.5 \pm 29.6)$ & $6.2 \pm 1.0(53.1 \pm 3.6)$ & $5.8 \pm 1.2(48.2 \pm 5.8)$ & $6.1 \pm 1.1(44.7 \pm 0.4)$ \\
\hline \multirow[t]{4}{*}{$\mathrm{JE}$ in $\mathrm{mm}$ and $(\%)$} & 1 & $6.2(50.7)$ & $2.0(19.9)$ & $1.6(11.9)$ & $1.5(12.5)$ \\
\hline & 2 & $0.9(7.6)$ & $2.7(25.4)$ & $1.6(14.1)$ & $1.5(12.5)$ \\
\hline & 3 & $5.0(40.6)$ & $4.9(33.9)$ & $3.7(33.9)$ & $3.6(22.0)$ \\
\hline & Mean $\pm \mathrm{SD}$ & $4.0 \pm 2.8(33.0 \pm 22.5)$ & $3.2 \pm 1.5(26.4 \pm 7.0)$ & $2.3 \pm 1.2(19.9 \pm 12.1)$ & $2.2 \pm 1.2(15.7 \pm 5.5)$ \\
\hline \multirow[t]{4}{*}{$\mathrm{CT}$ in $\mathrm{mm}$ and $(\%)$} & 1 & $0.4(2.9)$ & $0(0)$ & $0.2(1.1)$ & $0.1(1.1)$ \\
\hline & 2 & $0.1(0.4)$ & $0.3(2.5)$ & $0.6(5.5)$ & $0.2(1.6)$ \\
\hline & 3 & $0.1(1.2)$ & $0.1(0.7)$ & $0.3(2.8)$ & $0.4(2.4)$ \\
\hline & Mean \pm SD & $0.2 \pm 0.2(1.5 \pm 1.3)$ & $0.1 \pm 0.1(1.1 \pm 1.3)$ & $0.4 \pm 0.3(3.1 \pm 2.2)$ & $0.2 \pm 0.1(1.7 \pm 0.7)$ \\
\hline \multirow[t]{4}{*}{$\mathrm{NC}$ in $\mathrm{mm}$ and $(\%)$} & 1 & $5.1(41.6)$ & $2.8(27.3)$ & $3.9(29.9)$ & $5.0(41.3)$ \\
\hline & 2 & $2.6(23.1)$ & $2.0(18.5)$ & $3.8(32.6)$ & $5.8(47.2)$ \\
\hline & 3 & $3.3(26.9)$ & $1.8(12.4)$ & $4.3(39.7)$ & $5.4(32.9)$ \\
\hline & Mean \pm SD & $3.7 \pm 1.3(30.5 \pm 9.8)$ & $2.2 \pm 0.5(19.4 \pm 7.5)$ & $4.0 \pm 0.3(34.1 \pm 5.1)$ & $5.4 \pm 0.4(40.5 \pm 7.2)$ \\
\hline \multirow[t]{4}{*}{$\mathrm{NA}$ in $\mathrm{mm}$ and $(\%)$} & 1 & $3.3(26.9)$ & $2.4(23.4)$ & $3.0(23.1)$ & $4.9(40.8)$ \\
\hline & 2 & $2.1(18.1)$ & $1.6(14.7)$ & $3.1(26.6)$ & $4.8(39.2)$ \\
\hline & 3 & $1.6(13.2)$ & $0.6(4.2)$ & $2.8(25.4)$ & $5.3(32.3)$ \\
\hline & Mean $\pm \mathrm{SD}$ & $2.3 \pm 0.9(19.4 \pm 6.9)$ & $1.5 \pm 0.9(14.1 \pm 9.6)$ & $3.0 \pm 0.2(25.0 \pm 1.8)$ & $5.0 \pm 0.3(37.4 \pm 4.6)$ \\
\hline
\end{tabular}

ACS, absorbable collagen sponge; LRS, length of the root surface; TFL, tissue-free defect length, JE, junctional epithelial migration; CT, connective tissue adhesion; NC, new cementum; NA, new attachment formation.

and Osteogain/ACS groups. Com- furcation defects exhibiting a lower plete resolution of all furcation healing potential and by the difficuldefects was not achieved in any of the ties to ensure a plaque-free healing specimens. On the one hand, the incomplete regeneration may be explained by the large chronic-type, environment in this animal model (Caton et al. 1994, Donos et al. 2003). It has been extensively demonstrated that periodontal wound healing and the outcomes following conventional and regenerative periodontal surgery are negatively influenced by plaque accumulation of the wound area (Rosling et al. 1976, 
Nyman et al. 1977, Lindhe et al. 1995, Tonetti et al. 1996, Rossa et al. 2000, Gkranias et al. 2012). On the other hand, it cannot be excluded that the used ACS did not possess the optimal mechanical characteristics to ensure sufficient stability of the wound, subsequently resulting in a collapse of the mucoperiosteal flap and more limited space for regeneration (Susin et al. 2015). Although the expenses and demanding maintenance may restrict the broad use of non-human primates, the microbiological, immunological, and morphological features are quite similar to those of humans (Pellegrini et al. 2009). Furthermore, chronic periodontal defects with minimal spontaneous repair are valuable for evaluating new medical formulations or drugs as a putative periodontal regenerative therapy prior to clinical application in humans (Caton et al. 1994, Giannobile et al. 1994). The amount of new tissue formation obtained in the Emdogain/ACS and Osteogain/ACS groups was greater than those in the OFD and ACS groups in the present animal model. Furthermore, the migration of the junctional epithelium was more restricted in the Emdogain/ACS and Osteogain/ACS groups compared to the OFD and ACS groups. For the newly formed cementum, no distinct qualitative differences were observed between the Emdogain/ACS and the Osteogain/ACS group, they were composed of mixed cellular/acellular cementum (Araujo \& Lindhe 1998, Donos et al. 2003, Shirakata et al. 2007, Gkranias et al. 2012). Functionally oriented collagen fibres with many blood vessels in some parts along the denuded root surface were observed, and they appeared to be denser than those observed in the control and ACS groups. These findings are comparable to those of previous studies reporting that EMD histologically presented positive regeneration results in animals and human biopsies (Hammarström et al. 1997, Heijl et al. 1997, Mellonig 1999, Donos et al. 2003, Hovey et al. 2006, Shirakata et al. 2007, Gkranias et al. 2012, Ivanovic et al. 2014, Sculean et al. 2015).

Interestingly, the amount of the regenerated tissue (i.e. NBA, NC, and NA) was the greatest in the Osteogain/ACS group, superior to that obtained in the Emdogain/ACS group. This may be due to the fact that the ELISA assay demonstrated that a $20-60 \%$ significantly higher amount of total adsorbed amelogenin was found for the Osteogain/ACS group when compared to Emdogain/ ACS. Furthermore, the ACS loaded with Emdogain started to degrade in PBS by 3 days, whereas those precoated with Osteogain showed more stable properties. These findings suggest that Osteogain-adsorbed ACS not only maintains the sustained release of amelogenin but also provides an environment conducive to accelerating periodontal regeneration. Furthermore, the positive effects of Osteogain on periodontal regeneration may be explained by previous findings indicating that Osteogain significantly increased cell adhesion, proliferation, and differentiation of osteoblasts in vitro (Miron et al. 2016b), as well as promoted the upregulation of genes encoding BMP-2, TGF- $\beta 1$, collagen 1 and osteocalcin (Miron et al. 2016c).

Within their limits, the present data indicate that Osteogain possesses favourable physicochemical properties facilitating adsorption of amelogenin on ACS and may additionally enhance periodontal wound healing/regeneration when compared to Emdogain. None of the treatments achieved complete regeneration, that is, class III furcation still persisted after treatment. Further pre-clinical and clinical studies are thus warranted to evaluate the biologic and clinical value of this novel EMD formulation on periodontal wound healing/regeneration.

\section{Acknowledgements}

The authors wish to thank $\mathrm{Mr}$. Makoto Tanoue for animal technical support; Mr. Shinya Maeda, Mr. Keisuke Ishimaru, and Ms. Maya Iwase for the histological preparation of the specimens; Shin Nippon Biomedical Laboratories, Ltd, Kagoshima, Japan. Institut Straumann AG, (Basel, Switzerland) provided the Osteogain and Emdogain used in this study. The authors thank Dr. Stefano Tugulu and Dr. Benjamin E. Pippenger (Institut Straumann AG, Basel, Switzerland) for their help and scientific comments in conducting this study. Absorbable collagen sponge
Collacone $^{\circledR}$ ) was provided free of charge by Botiss Dental, Berlin, Germany.

\section{References}

Araujo, M. G. \& Lindhe, J. (1998) GTR treatment of degreeIII furcation defects following application of enamel matrix proteins. An experimental study in dogs. Journal of Clinical Periodontology 25, 524-530.

Bokan, I., Bill, J. S. \& Schlagenhauf, U. (2006) Primary flap closure combined with Emdogain alone or Emdogain and cerasorb in the treatment of intra-bony defects. Journal of Clinical Periodontology 33, 885-893.

Caton, J., Mota, L., Gandini, L. \& Laskaris, B. (1994) Non-human primate models for testing the efficacy and safety of periodontal regeneration procedures. Journal of Periodontology 65, 1143-1150.

Cochran, D. L., Jones, A. A., Lilly, L. C., Fiorellini, J. P. \& Howell, H. (2000) Evaluation of recombinant human bone morphogenetic protein-2 in oral applications including the use of endosseous implants: 3-year results of a pilot study in humans. Journal of Periodontology 71, 1241-1257.

Cochran, D. L., Jones, A., Heiji, L., Mellonig, J. T., Schoolfield, J. \& King, G. N. (2003) Periodontal regeneration with a combination of enamel matrix proteins and autogenous bone grafting. Journal of Periodontology 74, 1269-1281.

Donos, N., Sculean, A., Glavind, L., Reich, E. \& Karring, T. (2003) Wound healing of degree III furcation involvements following guided tissue regeneration and/or Emdogain. A histologic study. Journal of Clinical Periodontology 30, 1061-1068.

Giannobile, W. V., Finkelman, R. D. \& Lynch, S. E. (1994) Comparison of canine and nonhuman primate animal models for periodontal regenerative therapy: results following a single administration of PDGF/IGF-I. Journal of Periodontology 65, 1158-1168.

Gkranias, N. D., Graziani, F., Sculean, A. \& Donos, N. (2012) Wound healing following regenerative procedures in furcation degree III defects: histomorphometric outcomes. Clinical Oral Investigations 16, 239-249.

Gurinsky, B. S., Mills, M. P. \& Mellonig, J. T. (2004) Clinical evaluation of demineralized freeze-dried bone allograft and enamel matrix derivative versus enamel matrix derivative alone for the treatment of periodontal osseous defects in humans. Journal of Periodontology 75, 1309-1318.

Hammarström, L., Heijl, L. \& Gestrelius, S. (1997) Periodontal regeneration in a buccal dehiscence model in monkeys after application of enamel matrix proteins. Journal of Clinical Periodontology 24, 669-677.

Heijl, L., Heden, G., Svärdström, G. \& Östgren, A. (1997) Enamel matrix derivative (Emdogain $\left.{ }^{\circledR}\right)$ in the treatment of intrabony periodontal defects. Journal of Clinical Periodontology 24, 705-714

Hovey, L. R., Jones, A. A., McGuire, M., Mellonig, J. T., Schoolfield, J. \& Cochran, D. L. (2006) Application of periodontal tissue engineering using enamel matrix derivative and a human fibroblast-derived dermal substitute to stimulate periodontal wound healing in Class III furcation defects. Journal of Periodontology 77, 790-799

Ivanovic, A., Nikou, G., Miron, R. J., Nikolidakis, D. \& Sculean, A. (2014) Which biomaterials may promote periodontal regeneration in intrabony periodontal defects? A systematic 
review of preclinical studies. Quintessence International 45, 385-395.

Kim, Y. T., Wikesjö, U. M., Jung, U. W., Lee, J. S., Kim, T. G. \& Kim, C. K. (2013) Comparison between a $B$-tricalcium phosphate and an absorbable collagen sponge carrier technology for rhGDF-5-stimulated periodontal wound healing/regeneration. Journal of Periodontology 84, 812-820.

Kuru, B., Yilmaz, S., Argin, K. \& Noyan, U. (2006) Enamel matrix derivative alone or in combination with a bioactive glass in wide intrabony defects. Clinical Oral Investigations 10, 227-234.

Lekovic, V., Camargo, P. M., Weinlaender, M. Nedic, M., Aleksic, Z. \& Kenney, E. B. (2000) A comparison between enamel matrix proteins used alone or in combination with bovine porous bone mineral in the treatment of intrabony periodontal defects in humans. Journal of Periodontology 71, 1110-1116.

Lindhe, J., Pontoriero, R., Berglundh, T. \& Araujo, M. (1995) The effect of flap management and bioresorbable occlusive devices in GTR treatment of degree III furcation defects. An experimental study in dogs. Journal of Clinical Periodontology 22, 276-283.

MacNeill, S. R., Cobb, C. M., Rapley, J. W., Glaros, A. G. \& Spencer, P. (1999) In vivo comparison of synthetic osseous graft materials. A preliminary study. Journal of Clinical Periodontology 26, 239-245.

Matarasso, M., Iorio-Siciliano, V., Blasi, A. Ramaglia, L., Salvi, G. E. \& Sculean, A. (2015) Enamel matrix derivative and bone grafts for periodontal regeneration of intrabony defects. A systematic review and meta-analysis. Clinical Oral investigations 19, 1581-1593.

McPherson, J. M. (1992) The utility of collagenbased vehicles in delivery of growth factors for hard and soft tissue wound repair. Clinical Materials 9, 225-234.

Mellonig, J. T. (1999) Enamel matrix derivative for periodontal reconstructive surgery: technique and clinical and histologic case report. The International Journal of Periodontics and Restorative Dentistry 19, 8-19.

Miron, R. J., Guillemette, V., Zhang, Y., Chandad, F. \& Sculean, A. (2014) Enamel matrix derivative in combination with bone grafts: a review of the literature. Quintessence International 45, 475-487.

Miron, R. J., Bosshardt, D. D., Buser, D., Zhang, Y., Tugulu, S., Gemperli, A., Dard, M., Caluseru, O. M., Chandad, F. \& Sculean, A. (2015) Comparison of the capacity of enamel matrix derivative gel and enamel matrix derivative in liquid formulation to adsorb to bone grafting materials. Journal of Periodontology 86, 578-587.

Miron, R. J., Sculean, A., Cochran, D. L., Froum, S., Zucchelli, G., Nemcovsky, C., Donos, N., Lyngstadaas, S. P., Deschner, J., Dard, M., Stavropoulos, A., Zhang, Y., Trombelli, L., Kasaj, A., Shirakata, Y., Cortellini,

\section{Clinical Relevance}

Scientific rationale for the study: A new liquid carrier system for enamel matrix derivative (EMD) (Osteogain) has recently been developed to facilitate bone biomaterial mixing. This study evaluated the effect of Osteogain with absorbable collagen sponges (ACS)
P., Tonetti, M., Rasperini, G., Jepsen, S. \& Bosshardt, D. D. (2016a) 20 years of Enamel matrix derivative: the past, the present and the future. Journal of Clinical Periodontology 43, 668-683.

Miron, R. J., Fujioka-Kobayashi, M., Zhang, Y., Caballé-Serrano, J., Shirakata, Y., Bosshardt, D. D., Buser, D. \& Sculean, A. (2016b) Osteogain improves osteoblast adhesion, proliferation and differentiation on a bovine-derived natural bone mineral. Clinical Oral Implants Research. doi:10.1111/clr.12802.

Miron, R. J., Chandad, F., Buser, D., Sculean, A., Cochran, D. L. \& Zhang, Y. (2016c) Effect of enamel matrix derivative (EMD)-liquid on osteoblast and periodontal ligament cell proliferation and differentiation. Journal of Periodontology 87, 91-99.

Nyman, S., Lindhe, J. \& Rosling, B. (1977) Periodontal surgery in plaque-infected dentitions. Journal of Clinical Periodontology 4, 240-249.

Pellegrini, G., Seol, Y. J., Gruber, R. \& Giannobile, W. V. (2009) Pre-clinical models for oral and periodontal reconstructive therapies. Journal of Dental Research 88, 1065-1076.

Potijanyakul, P., Sattayasansakul, W., Pongpanich, S., Leepong, N. \& Kintarak, S. (2010) Effects of enamel matrix derivative on bioactive glass in rat calvarium defects. Journal of Oral Implantology 36, 195-204.

Rosling, B., Nyman, S., Lindhe, J. \& Jern, B. (1976) The healing potential of the periodontal tissues following different techniques of periodontal surgery in plaque-free dentitions. A 2-year clinical study. Journal of Clinical Periodontology 3, 233-250.

Rossa, C. Jr, Marcantonio, E. Jr, Cirelli, J. A., Marcantonio, R. A., Spolidorio, L. C. \& Fogo, J. C. (2000) Regeneration of Class III furcation defects with basic fibroblast growth factor (bFGF) associated with GTR. A descriptive and histometric study in dogs. Journal of Periodontology $71,775-784$

Sculean, A., Alesandri, R., Miron, R., Salvi, G. E. \& Bosshardt, D. D. (2011) Enamel matrix proteins and periodontal wound healing and regeneration. Clinical Advances in Periodontics 1, 101-117.

Sculean, A., Nikolidakis, D., Nikou, G., Ivanovic, A., Chapple, I. L. \& Stavropoulos, A. (2015) Biomaterials for promoting periodontal regeneration in human intrabony defects: a systematic review. Periodontology 2000 68, 182-216.

Shirakata, Y., Oda, S., Kinoshita, A., Kikuchi, S., Tsuchioka, H. \& Ishikawa, I. (2002) Histocompatible healing of periodontal defects after application of an injectable calcium phosphate bone cement. A preliminary study in dogs. Journal of Periodontology 73, 1043-1053.

Shirakata, Y., Yoshimoto, T., Goto, H., Yonamine, Y., Kadomatsu, H., Miyamoto, M., Nakamura, T., Hayashi, C. \& Izumi, Y. (2007) Favorable periodontal healing of 1-wall infrabony defects after application of calcium phos-

phate cement wall alone or in combination with enamel matrix derivative: a pilot study with canine mandibles. Journal of Periodontology 78, 889-898.

Stähli, A., Miron, R. J., Bosshardt, D. D., Sculean, A. \& Gruber, R. (2016) Collagen membranes adsorb the transforming growth factor$\beta$ receptor I kinase-dependent activity of enamel matrix derivative. Journal of Periodontology 87, 583-590.

Susin, C., Fiorini, T., Lee, J., De Stefano, J. A., Dickinson, D. P. \& Wikesjö, U. M. (2015) Wound healing following surgical and regenerative periodontal therapy. Periodontology 2000 68, 83-98.

Tonetti, M. S., Prato, G. P. \& Cortellini, P. (1996) Factors affecting the healing response of intrabony defects following guided tissue regeneration and access flap surgery. Journal of Clinical Periodontology 23, 548-556.

Tu, Y. K., Woolston, A. \& Faggison, C. M (2010) Do bone grafts or barrier membranes provide additional treatment effects for infrabony lesions treated with enamel matrix derivative? A network meta-analysis of randomizedcontrolled trials. Journal of Clinical Periodontology 37, 59-79.

Yamashita, M., Lazarov, M., Jones, A. A., Mealey, B. L., Mellonig, J. T. \& Cochran, D (2010) Periodontal regeneration using an anabolic peptide with two carriers in baboons. Journal of Periodontology 81, 727-736.

Yilmaz, S., Cakar, G., Yildirim, B. \& Sculean, A. (2010) Healing of two and three wall intrabony periodontal defects following treatment with an enamel matrix derivative combined with autogenous bone. Journal of Clinical Periodontology 37, 544-550.

Yoshinuma, N., Sato, S., Fukuyama, T., Murai, M. \& Ito, K. (2012) Ankylosis of nonresorbable hydroxyapatite graft material as a contributing factor in recurrent periodontitis. The International Journal of Periodontics and Restorative Dentistry 32, 331-336.

Zhang, Y., Jing, D., Buser, D., Sculean, A., Chandad, F. \& Miron, R. J. (2016) Bone grafting material in combination with Osteogain for bone repair: a rat histomorphometric study. Clinical Oral Investigations 20, 589-595.

Address:

Yoshinori Shirakata

Department of Periodontology

Kagoshima University Graduate School of

Medical and Dental Sciences

8-35-1 Sakuragaoka

Kagoshima 890-8544

Japan

E-mail: syoshi@dent.kagoshima-u.ac.jp

in chronic class III furcation defects in monkeys.

Principal findings: Statistically significantly higher amount of total adsorbed amelogenin was detected for Osteogain/ACS when compared to Emdogain, which yielded higher amounts of new connective tissue attachment and bone formation in furcation defects.

Practical implications: Osteogain/ ACS promoted periodontal wound healing/regeneration in class III furcation defects, thus warranting further evaluation in preclinical and clinical settings. 